\title{
ESTIMATED NITRIC OXIDE DENSITY IN AURORAS FROM GROUND-BASED PHOTOMETRIC DATA
}

\author{
Zh.V. Dashkevich \\ Polar Geophysical Institute RAS, \\ Apatity, Russia, zhanna@pgia.ru
}

\author{
V.E. Ivanov \\ Polar Geophysical Institute RAS, \\ Apatity,Russia,ivanov@pgia.ru
}

\begin{abstract}
In this paper, we numerically estimate the nitric oxide density in auroras, using photometric data on 427.8, 557.7, and $630.0 \mathrm{~nm}$ emission intensities. The data were obtained at midnight at observatories of the Polar Geophysical Institute. These estimates were made using a numerical modeling procedure with a time-dependent model of the auroral ionosphere [Dashkevich et al., 2017]. It is shown that the NO density in the maximum of the altitude profile is between $(1 \div 3.3) \cdot 10^{8} \mathrm{~cm}^{-3}$. The obtained estimates indicate the absence of a correlation
\end{abstract}

between the $[\mathrm{NO}]_{\max }$ values and $427.8 \mathrm{~nm}$ emission intensities.

Keywords: nitric oxide, ionospheric component densities, auroras, emission intensity, modeling, electron precipitation.

\section{INTRODUCTION}

The nitric oxide (NO) as a small component of the atmosphere plays an important role in the cycle of physico-chemical processes occurring during auroral electron precipitation in the ionosphere. There are no direct mass spectrometric measurements of NO density in auroras. The NO content in the auroral region was estimated by analyzing rocket measurements of ionic composition in the atmosphere or $\mathrm{NO}_{2}$ continuum intensity in the $520.0 \mathrm{~nm}$ emission [Sharp, 1978; Swider, Narcisi, 1977], as well as satellite measurements of NO intensity [Gerard, Barth, 1977; Gerard, Noel, 1986; Rusch, Barth, 1975; Siskind et al., 1989; Solomon et al., 1999; Stevens et al., 1997]. Figure 1 shows the [NO] altitude profiles obtained from measurements made directly in auroras. We can see that [NO] in the profile maximum can vary in the range of $10^{7}-10^{9} \mathrm{~cm}^{-3}$.

Dashkevich and Ivanov [2017] have described in detail a method capable of estimating [NO] in auroras from measurements of $1 \mathrm{NG} \mathrm{N}_{2}^{+}\left(B^{2} \Sigma_{\mathrm{u}}^{+}\right) 391.4 \mathrm{~nm}$, OI $\left({ }^{1} \mathrm{~S}\right) 557.7$, and OI $\left({ }^{1} \mathrm{D}\right) 630.0 \mathrm{~nm}$ emission intensities. This method relies on the fact that NO is an ion absorber $\mathrm{O}_{2}^{+}: \mathrm{O}_{2}^{+}+\mathrm{NO} \rightarrow \mathrm{NO}^{+}+\mathrm{O}_{2}$, whose dissociative recombination $\mathrm{O}_{2}^{+}+\mathrm{e} \rightarrow \mathrm{O}\left({ }^{1} \mathrm{~S}\right)+\mathrm{O}\left({ }^{1} \mathrm{D}\right)$ is one of the major sources of atomic oxygen in the ${ }^{1} \mathrm{~S}$ state, which, in turn, is a source of the $557.7 \mathrm{~nm}$ emission. In this paper, we present the [NO] estimates obtained from auroral measurements of $1 \mathrm{NG} \mathrm{N}_{2}^{+}\left(B^{2} \Sigma_{\mathrm{u}}^{+}\right) 427.8 \mathrm{~nm}$, OI $\left({ }^{1} \mathrm{~S}\right) 557.7 \mathrm{~nm}$, and OI $\left({ }^{1} \mathrm{D}\right) 630.0 \mathrm{~nm}$ emission intensities. The estimates were made by modeling the redistribution of internal freedom degrees of the excited atmospheric gas energy released in the ionosphere due to auroral electron precipitation. Using the measured 427.8, 557.7, and $630.0 \mathrm{~nm}$ emission intensities, we reconstructed the energy spectra of precipitated electrons and [NO], which represented the auroral emission intensities.

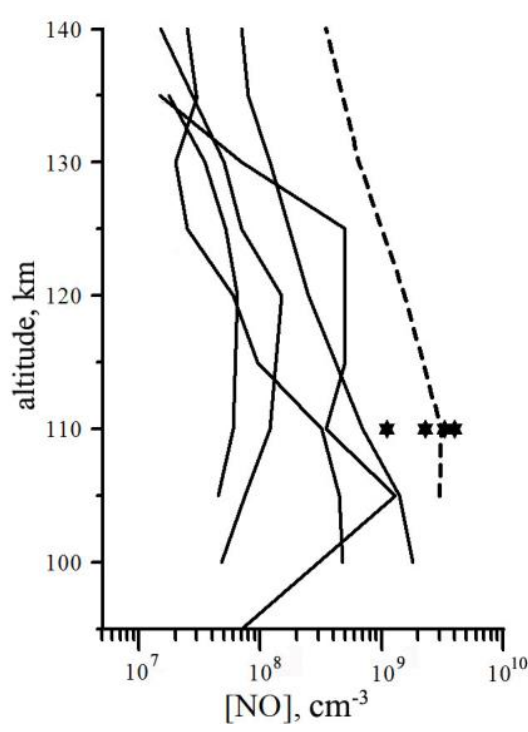

Figure 1. NO density as a function of height: asterisks indicate data from $\left[\right.$ Sharp, 1978] obtained from $\left[\mathrm{NO}^{+}\right] /\left[\mathrm{O}_{2}^{+}\right]$, the dashed line shows data on the $\mathrm{NO}_{2}$ continuum emission intensity from [Sharp, 1978]; solid lines, data from [Swider, Narcisi, 1977]

\section{MODELING RESULTS}

To estimate [NO], we have used photometric observations of $427.8,557.7$, and $630.0 \mathrm{~nm}$ emission intensities in auroras. The observations were made at observatories of the Polar Geophysical Institute in 1998-2001. Data on emission intensity at zenith were acquired at midnight, with aurora glowing and in the absence of cloudiness. The experimental data set contains 1335 measurements in eight nighttime series of observations at Lovozero Observatory $\left(\Phi^{\prime}=64.17^{\circ} \mathrm{N}\right)$ and 1200 measurements in eight nighttime series at the Tumanny Observatory $\left(\Phi^{\prime}=65.24^{\circ} \mathrm{N}\right)$. Details of the experimental data processing are given in [Dashkevich et al., 2006]. Here we note only that the $427.8 \mathrm{~nm}$ emission intensity is in the range $0.1-2 \mathrm{kR}$. The measurements averaged 
over the two stations and grouped in $427.8 \mathrm{~nm}$ emission intensities are presented in the first three columns of Table 1. The range of the $427.8 \mathrm{~nm}$ emission intensity variation is divided into intervals of $100 \mathrm{R}$.

[NO] and 427.8, 557.7, and $630.0 \mathrm{~nm}$ emission intensities in the electron precipitation region were calculated using a numerical modeling procedure with the physicochemical model describing the interaction between the main excited and ionized atmospheric components during electron precipitation [Dashkevich et al., 2017]. The model is based on the data available in the scientific literature and contains 56 physico-chemical reactions, including 23 reactions involving the odd nitrogen $\mathrm{NO}, \mathrm{N}\left({ }^{4} \mathrm{~S}\right), \mathrm{N}\left({ }^{2} \mathrm{D}\right), \mathrm{N}\left({ }^{2} \mathrm{P}\right)$, $\mathrm{N}^{+}$, and $\mathrm{NO}^{+}$. The reactions included in this model and describing the redistribution of the auroral electron energy released in the ionosphere are listed in Table 2. A distinctive feature of this model is a method for calculating vertical profiles of atmospheric gas excitation rates, which is based on the functional allowing us to analytically relate the altitude profiles of excited atmospheric components to the energy spectrum of precipitating electrons [Sergienko, Ivanov, 1993]. The numerical model calculates the altitude profiles of density of ionospheric components $\mathrm{N}_{2}^{+}, \mathrm{O}_{2}^{+}$ $\mathrm{O}^{+}\left({ }^{4} \mathrm{~S}\right), \mathrm{O}^{+}\left({ }^{2} \mathrm{D}\right), \mathrm{O}^{+}\left({ }^{2} \mathrm{P}\right), \mathrm{O}\left({ }^{1} \mathrm{D}\right), \mathrm{O}\left({ }^{1} \mathrm{~S}\right), \mathrm{N}\left({ }^{4} \mathrm{~S}\right), \mathrm{N}\left({ }^{2} \mathrm{D}\right)$, $\mathrm{N}\left({ }^{2} \mathrm{P}\right), \mathrm{NO}, \mathrm{NO}^{+}, \mathrm{N}^{+}, \mathrm{N}_{2}\left(\mathrm{~A}^{3} \Sigma_{\mathrm{u}}^{+}\right), \mathrm{N}_{2}\left(\mathrm{~B}^{3} \Pi_{\mathrm{g}}\right), \mathrm{N}_{2}\left(\mathrm{~W}^{3} \Delta_{\mathrm{u}}\right)$, $\mathrm{N}_{2}\left(\mathrm{~B}^{3} \Sigma_{\mathrm{u}}{ }^{-}\right), \mathrm{N}_{2}\left(\mathrm{C}^{3} \Pi_{\mathrm{u}}\right)$ and electrons in the auroral ionosphere; the temporal dynamics of density of ionospheric components; altitude profiles of intensity of the main auroral emissions, including 427.8, 557.7, and $630.0 \mathrm{~nm}$. Since the model ignores transfer effects, it can be applied to $\mathrm{E}$ and lower $\mathrm{F}$ layers of the ionosphere. Input parameters of the model are a model of the neutral atmosphere and parameters of precipitating electron flux.

In this work, we use the model of the neutral atmosphere MSIS-90 and the energy spectrum of precipitating electrons in the form of Maxwellian distribution

$$
N(E)=N_{0} E \exp \left(-E / E_{0}\right) / E_{0}^{2},
$$

where $N_{0}$ and $E_{0}$ are the precipitating electron flux at the upper boundary of the thermosphere $\left(\mathrm{cm}^{-2} \mathrm{~s}^{-1}\right)$ and the characteristic energy $(\mathrm{eV})$ respectively.

The procedure for reconstructing the [NO] vertical profiles, described in detail in [Dashkevich, Ivanov, 2017], consists of two stages. At the first stage, we determine parameters of precipitating electron flux (1), specified in the model, namely the characteristic energy $E_{0}$ and the particle flux $N_{0}$, which provide the 427.8 and $630.0 \mathrm{~nm}$ emission intensities observed in the experiment. The characteristic energy $E_{0}$ is estimated from the experimentally obtained intensity ratios $I_{630.0} / I_{427.8}$. As can be seen from [Dashkevich et al., 2006; Dashkevich, Ivanov, 2017; Eather, Mende, 1972; Rees, Luckey, 1974], $I_{630.0} / I_{427.8}$ is virtually independent of $N_{0}$ and is determined by $E_{0}$. Moreover, Dashkevich and Ivanov [2017] have shown that $I_{630.0} / I_{427.8}$ is also independent of [NO]. Figure 2 shows the $E_{0}$ dependence of $I_{630.0} /$ $I_{427.8}$ we use, which was calculated according to the physico-chemical model of the ionosphere [Dashkevich et al., 2017]. Values of $N_{0}$ fluxes are found from the condition

$$
I_{427.8}^{\exp }=N_{0} \iint \eta_{427.8}^{\text {theor }}(E, h) E \exp \left(-E / E_{0}\right) / E_{0}^{2} d E d h,
$$

where $I_{427.8}^{\exp }$ is the experimentally measured $427.8 \mathrm{~nm}$ emission intensity $\left(\mathrm{cm}^{-2} \mathrm{~s}^{-1}\right) ; \eta_{427.8}^{\text {theor }}(E, h) d E d h$ is the volume emission at $427.8 \mathrm{~nm}$, produced by precipitating electrons with energies from $E$ to $E+d E$ at a height $h$ in a layer $d h$ thick; $E_{0}$ is the characteristic energy $(\mathrm{eV})$.

\begin{tabular}{|c|c|c|c|c|c|c|}
\hline $\begin{array}{l}I_{427.8}, \text { Рл } \\
\text { exp. }\end{array}$ & $\begin{array}{l}I_{557.7}, \mathrm{R} \\
\text { exp. }\end{array}$ & $\begin{array}{c}I_{630.0}, \text { Рл } \\
\text { exp. }\end{array}$ & $\begin{array}{l}E_{0}, \mathrm{eV} \\
\text { calc. }\end{array}$ & $\begin{array}{c}N_{0}, 10^{9} \mathrm{~cm}^{-2} \mathrm{~s}^{-1} \\
\text { calc. }\end{array}$ & $\begin{array}{c}{[\mathrm{NO}]_{\max }, 10^{8} \mathrm{~cm}^{-3}} \\
\text { calc. }\end{array}$ & $\begin{array}{l}I_{557.7}, \mathrm{R} \\
\text { calc. }\end{array}$ \\
\hline 150 & 782 & 273 & 1039 & 0.5 & 1.6 & 780 \\
\hline 250 & 1330 & 365 & 1116 & 0.8 & 1.6 & 1330 \\
\hline 350 & 1845 & 403 & 1291 & 0.9 & 1.8 & 1845 \\
\hline 450 & 2437 & 475 & 1370 & 1.1 & 1.7 & 2432 \\
\hline 550 & 2945 & 490 & 1541 & 1.2 & 2.3 & 2941 \\
\hline 650 & 3551 & 544 & 1607 & 1.3 & 2.2 & 3543 \\
\hline 750 & 4075 & 650 & 1559 & 1.5 & 2.2 & 4072 \\
\hline 850 & 4930 & 609 & 1780 & 1.5 & 1.5 & 4927 \\
\hline 950 & 5567 & 578 & 1987 & 1.5 & 1.4 & 5554 \\
\hline 1100 & 6683 & 737 & 1858 & 1.9 & 1.0 & 6679 \\
\hline 1350 & 7755 & 744 & 2102 & 2.0 & 1.7 & 7754 \\
\hline 1700 & 9243 & 745 & 2465 & 2.1 & 3.3 & 9223 \\
\hline
\end{tabular}

Modeling results 
Reactions of interaction of atmospheric ions with excited components in auroras

\begin{tabular}{|c|c|c|}
\hline $\mathrm{N}_{2}^{+}$ & $\mathrm{O}^{+}\left({ }^{2} \mathrm{P}\right)$ & $\mathrm{N}\left({ }^{4} \mathrm{~S}\right)$ \\
\hline $\mathrm{N}_{2}^{+}+\mathrm{O}_{2} \rightarrow \mathrm{N}_{2}+\mathrm{O}_{2}^{+}$ & $\mathrm{O}^{+}\left({ }^{2} \mathrm{P}\right)+\mathrm{N}_{2} \rightarrow \mathrm{O}^{+}\left({ }^{4} \mathrm{~S}\right)+\mathrm{N}_{2}$ & $\mathrm{~N}\left({ }^{4} \mathrm{~S}\right)+\mathrm{O}_{2} \rightarrow \mathrm{NO}+\mathrm{O}$ \\
\hline $\mathrm{N}_{2}^{+}+\mathrm{O} \rightarrow \mathrm{N}_{2}+\mathrm{O}^{+}\left({ }^{4} \mathrm{~S}\right)$ & $\mathrm{O}^{+}\left({ }^{2} \mathrm{P}\right)+\mathrm{N}_{2} \rightarrow \mathrm{N}_{2}^{+}+\mathrm{O}$ & $\mathrm{N}\left({ }^{4} \mathrm{~S}\right)+\mathrm{NO} \rightarrow \mathrm{N}_{2}+\mathrm{O}$ \\
\hline $\mathrm{N}_{2}^{+}+\mathrm{O} \rightarrow \mathrm{NO}^{+}+\mathrm{N}\left({ }^{2} \mathrm{D}\right)$ & $\mathrm{O}^{+}\left({ }^{2} \mathrm{P}\right)+\mathrm{O} \rightarrow \mathrm{O}^{+}\left({ }^{4} \mathrm{~S}\right)+\mathrm{O}$ & $\mathrm{N}\left({ }^{2} \mathrm{D}\right)$ \\
\hline $\mathrm{N}_{2}^{+}+\mathrm{NO} \rightarrow \mathrm{N}_{2}+\mathrm{NO}^{+}$ & $\mathrm{O}^{+}\left({ }^{2} \mathrm{P}\right)+\mathrm{O}_{2} \rightarrow \mathrm{O}_{2}^{+}+\mathrm{O}$ & $\mathrm{N}\left({ }^{2} \mathrm{D}\right)+\mathrm{O}_{2} \rightarrow \mathrm{NO}+\mathrm{O}\left({ }^{3} \mathrm{P},{ }^{1} \mathrm{D}\right)$ \\
\hline $\mathrm{N}_{2}^{+}+\mathrm{e} \rightarrow \mathrm{N}\left({ }^{4} \mathrm{~S}\right)+\mathrm{N}\left({ }^{2} \mathrm{D}\right)$ & $\mathrm{O}^{+}\left({ }^{2} \mathrm{P}\right) \rightarrow \mathrm{O}^{+}\left({ }^{2} \mathrm{D}\right)+\mathrm{h} v$ & $\mathrm{~N}\left({ }^{2} \mathrm{D}\right)+\mathrm{O} \rightarrow \mathrm{N}\left({ }^{4} \mathrm{~S}\right)+\mathrm{O}\left({ }^{3} \mathrm{P},{ }^{1} \mathrm{D}\right)$ \\
\hline $\mathrm{O}_{2}^{+}$ & $\mathrm{O}^{+}\left({ }^{2} \mathrm{P}\right) \rightarrow \mathrm{O}^{+}\left({ }^{4} \mathrm{~S}\right)+\mathrm{h} v$ & $\mathrm{~N}\left({ }^{2} \mathrm{D}\right)+\mathrm{NO} \rightarrow \mathrm{N}_{2}+\mathrm{O}$ \\
\hline $\mathrm{O}_{2}^{+}+\mathrm{e} \rightarrow \mathrm{O}\left({ }^{1} \mathrm{~S}\right)+\mathrm{O}\left({ }^{1} \mathrm{D}\right)$ & $\mathrm{O}^{+}\left({ }^{2} \mathrm{P}\right)+\mathrm{e} \rightarrow \mathrm{O}^{+}\left({ }^{2} \mathrm{D}\right)+\mathrm{e}$ & $\mathrm{N}\left({ }^{2} \mathrm{D}\right)+\mathrm{NO} \rightarrow \mathrm{N}\left({ }^{4} \mathrm{~S}\right)+\mathrm{NO}$ \\
\hline $\mathrm{O}_{2}^{+}+\mathrm{N}\left({ }^{4} \mathrm{~S}\right) \rightarrow \mathrm{NO}^{+}+\mathrm{O}\left({ }^{1} \mathrm{~S}\right)$ & $\mathrm{O}^{+}\left({ }^{2} \mathrm{P}\right)+\mathrm{e} \rightarrow \mathrm{O}^{+}\left({ }^{4} \mathrm{~S}\right)+\mathrm{e}$ & $\mathrm{N}\left({ }^{2} \mathrm{D}\right)+\mathrm{e} \rightarrow \mathrm{N}\left({ }^{4} \mathrm{~S}\right)+\mathrm{e}$ \\
\hline $\mathrm{O}_{2}^{+}+\mathrm{NO} \rightarrow \mathrm{NO}^{+}+\mathrm{O}_{2}$ & $\mathrm{O}\left({ }^{1} \mathrm{D}\right)$ & $\mathrm{N}\left({ }^{2} \mathrm{D}\right) \rightarrow \mathrm{N}\left({ }^{4} \mathrm{~S}\right)+\mathrm{h} v$ \\
\hline $\mathrm{O}_{2}^{+}+\mathrm{N}\left({ }^{2} \mathrm{D}\right) \rightarrow \mathrm{NO}^{+}+\mathrm{O}$ & $\mathrm{O}\left({ }^{1} \mathrm{D}\right)+\mathrm{N}_{2} \rightarrow \mathrm{O}+\mathrm{N}_{2}$ & $\mathrm{~N}\left({ }^{2} \mathrm{P}\right)$ \\
\hline $\mathrm{O}^{+}\left({ }^{4} \mathrm{~S}\right)$ & $\mathrm{O}\left({ }^{1} \mathrm{D}\right)+\mathrm{O}_{2} \rightarrow \mathrm{O}+\mathrm{O}_{2}$ & $\mathrm{~N}\left({ }^{2} \mathrm{P}\right)+\mathrm{O}_{2} \rightarrow \mathrm{NO}+\mathrm{O}\left({ }^{1} \mathrm{~S},{ }^{1} \mathrm{D},{ }^{3} \mathrm{P}\right)$ \\
\hline $\mathrm{O}^{+}\left({ }^{4} \mathrm{~S}\right)+\mathrm{N}_{2} \rightarrow \mathrm{NO}^{+}+\mathrm{N}\left({ }^{4} S\right)$ & $\mathrm{O}\left({ }^{1} \mathrm{D}\right)+\mathrm{O} \rightarrow \mathrm{O}+\mathrm{O}$ & $\mathrm{N}\left({ }^{2} \mathrm{P}\right)+\mathrm{O} \rightarrow \mathrm{N}\left({ }^{2} \mathrm{D}\right)+\mathrm{O}$ \\
\hline $\mathrm{O}^{+}\left({ }^{4} \mathrm{~S}\right)+\mathrm{O}_{2} \rightarrow \mathrm{O}_{2}^{+}+\mathrm{O}$ & $\mathrm{O}\left({ }^{1} \mathrm{D}\right) \rightarrow \mathrm{O}+\mathrm{h} v$ & $\mathrm{~N}\left({ }^{2} \mathrm{P}\right) \rightarrow \mathrm{N}\left({ }^{2} \mathrm{D}\right)+\mathrm{h} v$ \\
\hline $\mathrm{O}^{+}\left({ }^{4} \mathrm{~S}\right)+\mathrm{NO} \rightarrow \mathrm{NO}^{+}+\mathrm{O}$ & $\mathrm{O}\left({ }^{1} \mathrm{D}\right)+\mathrm{e} \rightarrow \mathrm{O}+\mathrm{e}$ & $\mathrm{N}\left({ }^{2} \mathrm{P}\right) \rightarrow \mathrm{N}\left({ }^{4} \mathrm{~S}\right)+\mathrm{h} v$ \\
\hline $\mathrm{O}^{+}\left({ }^{2} \mathrm{D}\right)$ & $\mathrm{O}\left({ }^{1} \mathrm{~S}\right)$ & $\mathrm{N}\left({ }^{2} \mathrm{P}\right)+\mathrm{NO} \rightarrow \mathrm{N}_{2}+\mathrm{O}$ \\
\hline $\mathrm{O}^{+}\left({ }^{2} \mathrm{D}\right)+\mathrm{N}_{2} \rightarrow \mathrm{N}_{2}^{+}+\mathrm{O}$ & $\mathrm{O}\left({ }^{1} \mathrm{~S}\right)+\mathrm{O} \rightarrow \mathrm{O}+\mathrm{O}$ & $\mathrm{N}^{+}$ \\
\hline $\mathrm{O}^{+}\left({ }^{2} \mathrm{D}\right)+\mathrm{N}_{2} \rightarrow \mathrm{NO}^{+}+\mathrm{N}\left({ }^{4} \mathrm{~S}\right)$ & $\mathrm{O}\left({ }^{1} \mathrm{~S}\right) \rightarrow \mathrm{O}\left({ }^{1} \mathrm{D}\right)+\mathrm{h} v$ & $\mathrm{~N}^{+}+\mathrm{O}_{2} \rightarrow \mathrm{O}_{2}^{+}+\mathrm{N}\left({ }^{4} \mathrm{~S},{ }^{2} \mathrm{D}\right)$ \\
\hline $\mathrm{O}^{+}\left({ }^{2} \mathrm{D}\right)+\mathrm{O}_{2} \rightarrow \mathrm{O}_{2}^{+}+\mathrm{O}$ & $\mathrm{O}\left({ }^{1} \mathrm{~S}\right) \rightarrow \mathrm{O}+\mathrm{h} v$ & $\mathrm{~N}^{+}+\mathrm{O}_{2} \rightarrow \mathrm{NO}^{+}+\mathrm{O}\left({ }^{1} \mathrm{D},{ }^{1} \mathrm{~S}\right)$ \\
\hline $\mathrm{O}^{+}\left({ }^{2} \mathrm{D}\right)+\mathrm{O}_{2} \rightarrow \mathrm{O}^{+}\left({ }^{4} \mathrm{~S}\right)+\mathrm{O}_{2}$ & $\mathrm{O}\left({ }^{1} \mathrm{~S}\right)+\mathrm{O}_{2} \rightarrow \mathrm{O}+\mathrm{O}_{2}$ & $\mathrm{~N}^{+}+\mathrm{O}_{2} \rightarrow \mathrm{O}^{+}\left({ }^{4} \mathrm{~S}\right)+\mathrm{NO}$ \\
\hline $\mathrm{O}^{+}\left({ }^{2} \mathrm{D}\right)+\mathrm{O} \rightarrow \mathrm{O}^{+}\left({ }^{4} \mathrm{~S}\right)+\mathrm{O}$ & $\mathrm{O}\left({ }^{1} \mathrm{~S}\right)+\mathrm{NO} \rightarrow \mathrm{O}+\mathrm{NO}$ & $\mathrm{N}^{+}+\mathrm{O} \rightarrow \mathrm{O}^{+}\left({ }^{4} \mathrm{~S}\right)+\mathrm{N}\left({ }^{4} \mathrm{~S}\right)$ \\
\hline $\mathrm{O}^{+}\left({ }^{2} \mathrm{D}\right)+\mathrm{e} \rightarrow \mathrm{O}^{+}\left({ }^{4} \mathrm{~S}\right)+\mathrm{e}$ & $\mathrm{NO}^{+}$ & $\mathrm{N}_{2}\left(\mathrm{~A}^{3} \Sigma_{\mathrm{u}}^{+}\right)$ \\
\hline $\mathrm{O}^{+}\left({ }^{2} \mathrm{D}\right) \rightarrow \mathrm{O}^{+}\left({ }^{4} \mathrm{~S}\right)+\mathrm{h} v$ & $\mathrm{NO}^{+}+\mathrm{e} \rightarrow \mathrm{O}+\mathrm{N}\left({ }^{4} \mathrm{~S},{ }^{2} \mathrm{D}\right)$ & $\mathrm{N}_{2}\left(\mathrm{~A}^{3} \Sigma_{\mathrm{u}}^{+}\right)+\mathrm{O} \rightarrow \mathrm{N}_{2}+\mathrm{O}\left({ }^{1} \mathrm{~S}\right)$ \\
\hline
\end{tabular}

Note. Reaction rate constants are shown in [Dashkevich et al., 2017].

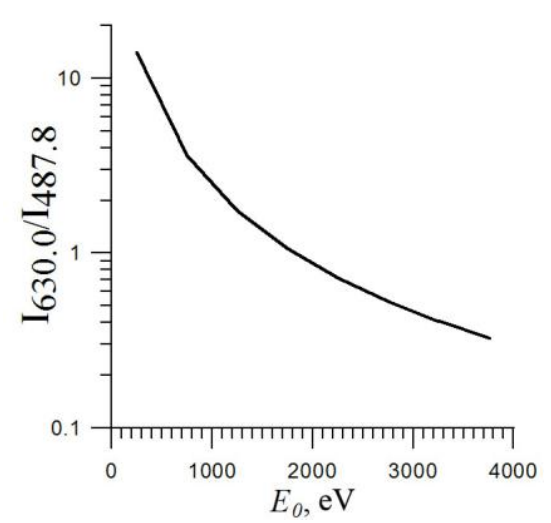

Figure 2 . The intensity ratio $I_{630.0} / I_{427.8}$ versus $E_{0}$

The $E_{0}$ and $N_{0}$ values thus determined provide the experimentally observed intensities $I_{427.8}$ and $I_{630.0}$ for precipitating electrons with the given energy spectrum in the form of (1).

The second stage involves calculating altitude profiles of the $557.7 \mathrm{~nm}$ emission intensity and respective vertical distributions of [NO]. The absolute values of
[NO] for each event are determined by the condition that the best agreement is obtained between the calculated values of $I_{557.7}$ and those measured in the experiment. The [NO] vertical profiles thus modeled are depicted in Figure 3. The calculated values of $[\mathrm{NO}]_{\max }$ in

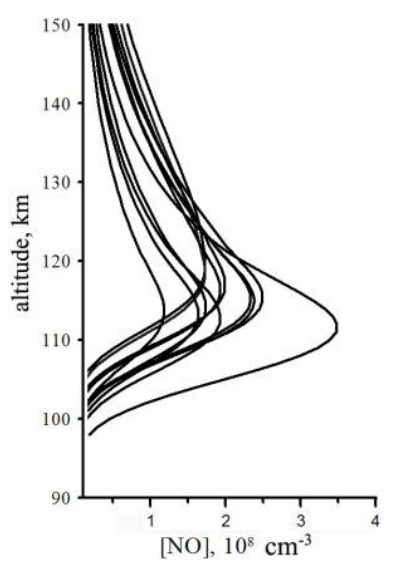

Figure 3. Modeled altitude profiles of [NO]. Each curve corresponds to one pair of ratios $I_{630.0} / I_{427.8}$ and $I_{557.7} / I_{427.8}$ 
the maximum of the altitude profile are shown in Table 1. For comparison we give the modeled values of $I_{557.7}$. Estimates of [NO] in auroras, obtained from photometric measurements of $I_{427.8}, I_{557.7}$, and $I_{630.0}$, are seen to be within $(1 \div 3.3) 10^{8} \mathrm{~cm}^{-3}$ for $I_{427.8}$ ranging from 0.1 to $2 \mathrm{kR}$. The results agree satisfactorily with the [NO] estimates, obtained from the analysis of the ion composition in auroras, measured in rocket experiments [Sharp, 1978; Swider, Narcisi, 1977].

It should also be noted that the results we got indicate that there is no direct correlation between $I_{427.8}$ and $[\mathrm{NO}]_{\max }$. This fact has been discussed by Gerard and Barth [1977]. The cause of the absence of this correlation can be explained by the long lifetime of NO, which can accumulate in the ionosphere. Therefore, [NO] in each particular aurora may be determined not only by the duration and intensity of precipitated electron fluxes, but also by the duration and intensity of auroral activity preceding the event under study.

\section{CONCLUSIONS}

This paper presents numerical estimates of the NO content in auroras, obtained from ground photometric measurements of $427.8,557.7$, and $630.0 \mathrm{~nm}$ emission intensities in the midnight sector of the auroral oval. We have shown that $[\mathrm{NO}]$ in the maximum of its vertical profile $[\mathrm{NO}]_{\max }$ is within $(1 \div 3.3) \cdot 10^{8} \mathrm{~cm}^{-3}$. We found no direct correlation between $[\mathrm{NO}]_{\max }$ and $427.8 \mathrm{~nm}$ emission intensities.

\section{REFERENCES}

Dashkevich Zh.V., Ivanov V.E. Estimation of the NO concentration in the polar region from 391.4, 557.7, and 630.0 nm emission intensities. Cosmic Res. 2017, vol. 55, no. 5, pp. 318-322. DOI: 10.1134/S0010952517050045.

Dashkevich Zh.V., Zverev V.L., Ivanov V.E. Ratios of $I_{630.0} / I_{427.8}$ and $I_{557.7} / I_{427.8}$ emission intensities in auroras. Geomagnetism and Aeronomy. 2006, vol. 46, no. 3, pp. 366370. DOI: $10.1134 /$ S001679320603011X.

Dashkevich Zh.V., Ivanov V.E, Sergienko T.I., Kozelov B.V. Physicochemical model of the auroral ionosphere.
Cosmic Res. 2017, vol. 55, no. 2, pp. 88-100. DOI: 10.1134/ S0010952517020022.

Eather R.H., Mende S.B. Systematics in auroral energy spectra. J. Geophys. Res. 1972, vol. 77, no. 4, pp. 660-673. DOI: 10.1029/JA077i004p00660

Gérard J.-C., Barth C.A. High-latitude nitric oxide in the lower thermosphere. J. Geophys. Res. 1977, vol. 82, no. 4, pp. 674-680. DOI: 10.1029/JA082i004p00674.

Gérard J.-C., Noel C.E. AE-D measurements of the NO geomagnetic latitudinal distribution and contamination by $\mathrm{N}^{+}\left({ }^{5} \mathrm{~S}\right)$ emission. J. Geophys. Res. 1986, vol. 91, no. A9, pp. 10136-10140. DOI: 10.1029/JA091iA09p10136.

Rees M.H., Luckey D. Auroral electron energy derived from ratio of spectroscopic emissions. 1. Model computations. J. Geophys. Res. 1974, vol. 79, no. 34, pp. 5181-5186. DOI: 10.1029/JA079i034p05181.

Rusch D.W., Barth C.A. Satellite measurements of nitric oxide in the polar region. J. Geophys. Res. 1975, vol. 80, no. 25, pp. 3719-3721. DOI: 10.1029/JA080i025p03719.

Sergienko T.I., Ivanov V.E. A new approach to calculate the excitation of atmospheric gases by auroral electron impact. Ann. Geophys. 1993, vol. 11, no. 8, pp. 717-727.

Sharp W.E. $\mathrm{NO}_{2}$ continuum in aurora. J. Geophys. Res. 1978, vol. 83, no. 9, pp. 4373-4376. DOI: 10.1029/JA083iA09p04373.

Siskind D.E., Barth C.A., Evans D.S., Roble R.G. The response of the thermospheric nitric oxide to an auroral storm. 2 . Auroral latitudes. J. Geophys. Res. 1989, vol. 94, no. A12, pp.16899-16911. DOI: 10.1029/JA094iA12p16899.

Solomon C.S., Barth C.A., Bailey S.M. Auroral production of nitric oxide measured by the SNOE satellite. Geophys. Res. Lett. 1999, vol. 26, pp. 1259-1262. DOI: 10.1029/1999GL900235.

Stevens M.H., Conway R.R., Cardon J.G., Russell J.M. MAHRSI observations of nitric oxide in the mesosphere and lower thermosphere. Geophys. Res. Lett. 1997, vol. 24, pp. 3213-3216. DOI: 10.1029/97GL03257.

Swider W., Narcisi R.S. Auroral E-region: Ion composition and nitric oxide. Planet. Space Sci. 1977, vol. 25, no. 2, pp. 103-116. DOI: 10.1016/0032-0633(77)90014-9.

How to cite this article

Dashkevich Zh.V., Ivanov V.E. Estimated nitric oxide density in auroras from ground-based photometric data. Solar-Terrestrial Physics. 2019. Vol. 5. Iss. 1. P. 58-61. DOI: 10.12737/stp-51201908. 